\title{
The Arabidopsis Gain-of-Function Mutant ssi4 Requires RAR1 and SGT1b Differentially for Defense Activation and Morphological Alterations
}

\author{
Fasong Zhou, ${ }^{1}$ Stephen Mosher, ${ }^{1}$ Miaoying Tian, ${ }^{1}$ Giovanna Sassi, ${ }^{1}$ Jane Parker, ${ }^{2}$ Daniel F. Klessig \\ ${ }^{1}$ Boyce Thompson Institute for Plant Research, Tower Road, Ithaca, NY 14850, U.S.A.; ${ }^{2}$ Department of Plant-Microbe \\ Interactions, Max-Planck Institute for Plant Breeding Research, Carl-von-Linne-Weg 10, 50829 Cologne, Germany
}

Submitted 16 July 2007. Accepted 21 September 2007.

\begin{abstract}
A gain-of-function mutation in resistance $(R)$ gene $\mathrm{SSI} 4$ causes constitutive activation of defense responses, spontaneous necrotic lesion formation, enhanced resistance against virulent pathogens, and a severe dwarf phenotype. Genetic analysis revealed that ssi4-induced $\mathrm{H}_{2} \mathrm{O}_{2}$ accumulation and spontaneous cell death require $R A R 1$, whereas ssi4-mediated stunting is dependent on $S G T 1 b$. By contrast, both $R A R 1$ and $S G T 1 b$ are required in a genetically additive manner for ssi4-induced disease resistance, SA accumulation, and lesion formation after pathogen infection. These data point to cooperative yet distinct functions of RAR1 and SGT1b in responses conditioned by a deregulated nucleotide-binding leucine-rich repeat protein. We also found that $R A R I$ and $S G T 1 b$ together contribute to basal resistance because an ssi4 rarl sgtlb triple mutant exhibited enhanced susceptibility to virulent pathogen infection compared with wild-type SSI4 plants. All ssi4-induced phenotypes were suppressed when plants were grown at $22^{\circ} \mathrm{C}$ under high relative humidity. However, low temperature $\left(16^{\circ} \mathrm{C}\right)$ triggered ssi4-mediated cell death via an $R A R 1$-dependent pathway even in the presence of high humidity. Thus, multiple environmental factors impact on ssi4 signaling, as has been observed for other constitutive defense mutants and $R$ gene-triggered pathways.
\end{abstract}

Additional keywords: Arabidopsis, dwarfism

Nucleotide binding-leucine rich repeat (NB-LRR) proteins encoded by a major class of race-specific disease resistance $(R)$ genes recognize their cognate avirulence (AVR) factors directly or indirectly and trigger a hypersensitive response (HR) and innate immunity (Jones and Dangl 2006). Based on

Corresponding author: Daniel F. Klessig; Fax +1 607254 6779, E-mail dfk8@cornell.edu

Present address of F. Zhou: Ceres, Inc., 1535 Rancho Conejo Blvd., Thousand Oaks, CA 91320, U.S.A.

Present address of S. Mosher: Department of Cell and Systems Biology, University of Toronto, 25 Wilcocks Street, Toronto, Ontario M5S 3B2, Canada.

Present address of M. Tian: Department of Plant Pathology, Michigan State University, 105 Center for Integrated Plants Systems, East Lansing, 48824, U.S.A.

Present address of G. Sassi: Department of Plant Pathology, Cornell University, Tower Road, Ithaca, NY 14853, U.S.A. their N-terminal sequences, NB-LRR proteins can be divided into two subgroups, one sharing homology to Drosophila Toll protein and mammalian interleukin-1 receptors (the TIR domain) and the other containing a coiled-coil (CC) motif. Of $149 \mathrm{NB}-L R R$ genes identified in the Arabidopsis genome, 83 belong to the TIR-NB-LRR subgroup, 51 to the CC-NB-LRR subgroup, and the remainder either lack TIR or CC homology or contain additional domains (Meyers et al. 2003). By contrast, none of the $480 N B-L R R$ genes identified in the rice genome have a TIR structure (Zhou et al. 2004b).

Identification of the ssi4 (suppressor of salicylic acid insensitive4) mutant that contains a gain-of-function mutation in a $T I R-N B-L R R$-type $R$ gene provided an opportunity to study signal transduction and phenotypic changes caused by $R$ gene activation (Shirano et al. 2002; Zhou et al. 2004a). The ssi4 plants display many characteristics of constitutively active defense mutants, such as elevated expression of pathogenesisrelated $(P R)$ genes, broad-spectrum resistance to virulent pathogens, spontaneous necrotic lesion formation, and a severe dwarf morphology (Shirano et al. 2002). Epitasis analysis indicated that $s$ si4-induced $P R$ gene expression and disease resistance is salicylic acid (SA) and EDS1 dependent but NPRI and NDRI independent (Shirano et al. 2002). When grown under standard conditions, ssi4 accumulates elevated $\mathrm{H}_{2} \mathrm{O}_{2}$ and $\mathrm{SA}$ levels prior to lesion formation and displays constitutive activation of the MAP kinases AtMPK6 and AtMPK3 (Zhou et al. 2004a). All ssi4-induced responses are suppressed by high relative humidity (HRH; 95\%) (Zhou et al. 2004a), raising the possibility that a humidity-sensitive factor (HSF) functions at an early point in the ssi4 signaling pathway.

To unravel further ssi4 signaling processes leading to disease resistance and developmental defects, we assessed the involvement of two known plant defense regulators, RARl and SGT1. $R A R l$ encodes a small protein with two cysteine and histidinerich, zinc-binding domains (CHORD I and II) that was first identified as a rate-limiting positive regulator of multiple $R$ gene-triggered responses (Liu et al. 2002a; Muskett et al. 2002; Shirasu et al. 1999; Tornero et al. 2002). SGT1 was characterized in yeast as a factor required for kinetochore assembly and SKP1/Cullin1/F-box (SCF) E3 ubiquitin ligase activity through interaction with SKP1 and the molecular chaperone HSP90 (Catlett and Kaplan 2006; Kitagawa et al. 1999). Accordingly, SGT1 has domains resembling the fold structures of two HSP90 co-chaperones Sti1/Hop and p23 (Garcia-Ranea et al. 2002; Muskett and Parker 2003). SGT1 proteins from yeast, humans, and plants are highly sequence related and the ability of plant or human SGT1 to complement cell-cycle defects in yeast sgtl mutants suggests that their bio- 
logical properties are conserved (Azevedo et al. 2002; Kitigawa et al. 1999). In Arabidopsis, two highly similar SGT1 genes ( $S G T 1 a$ and $S G T 1 b$ ) are expressed that, together, are essential for early development (Azevedo et al. 2006). Although only $S G T 1 b$ has been implicated genetically in plant $R$ gene-triggered responses, overexpression of SGT1a complements an $s g t 1 b$ null mutant, suggesting that both Arabidopsis SGT1 proteins are involved in signaling resistance (Azevedo et al. 2006).

The precise modes of action for RAR1 and SGT1 in plants are unclear. However, both RAR1 and SGT1 interact transiently with HSP90 (Hubert et al. 2003; Liu et al. 2004; Takahashi et al. 2003), suggesting that these proteins assist the assembly of functional $\mathrm{R}$ protein complexes. Consistent with this possibility, RAR1 is needed to stabilize the NB-LRR proteins MLA1 and MLA6 (barley) and RPM1 (Arabidopsis) in their preactivation states (Bieri et al. 2004; Holt et al. 2005; Hubert et al. 2003; Tornero et al. 2002) and SGT1 stabilizes $\mathrm{Rx}$ in tobacco (Azevedo et al. 2006). Genetic analyses established that certain $R$ genes require either $S G T 1 b$ or $R A R I$ to signal resistance (Muskett and Parker 2003). For certain $R$ genes, combined rarl and sgtlb mutations were genetically additive or antagonistic (Austin et al. 2002; Azevedo et al. 2002; Holt et al. 2005). These data imply that RAR1 and SGT1 have distinct but potentially interactive functions in resistance signaling that may depend on the accumulation and folding characteristics of particular NB-LRR proteins.

Plant RAR1 and SGT1 also were shown to interact with subunits of the COP9 signalosome, a multiprotein complex that regulates ubiquitin-proteasome-mediated degradation (Azevedo et al. 2002; Liu et al. 2002b). In addition, barley SGT1 interacts with SKP1 and CUL1, two core subunits of the SCF E3 ligase, another complex involved in protein degradation (Azevedo et al. 2002). Silencing NbSKPl or the NbCOP9 signalosome in Nicotiana benthamiana compromised $\mathrm{N}$-mediated resistance to Tobacco mosaic virus (TMV); therefore, ubiquitin-mediated protein degradation appears to play a role in plant defense, possibly by targeting a negative regulator for degradation (Liu et al. 2002b). Furthermore, the observation that SGT1 interacts with RAR1, SKP1, and CUL1 whereas RAR1 interacts only with SGT1 suggests that SGT1 functions independently of RAR1 via its interaction with the SCF E3 ligase (Azevedo et al. 2002). Indeed, $S G T 1 b$ but not RARl is required for the activities of the Arabidopsis SCF E3 ligases $\mathrm{SCF}_{-}{ }^{\mathrm{TIR} 1}$ and $\mathrm{SCF}-{ }^{\mathrm{COI} 1}$ that regulate responses to the phytohormones auxin and jasmonic acid, respectively (Gray et al. 2003). Together, these data suggest that SGT1 works in conjunction with RAR1 to mediate R protein complex assembly or maturation but also suggest additional functions of SGT1 in regulating the ubiquitination machinery that may, for example, remove a negative regulator of $\mathrm{R}$ protein function or promote downstream signal transduction.

In this study, we investigated the roles of RARl and SGTIb in ssi4-mediated disease resistance, cell death, and development. Our results reveal overlapping yet distinct functions of $R A R I$ and $S G T 1 b$ in signaling from a deregulated NB-LRR protein. This distinction is particularly evident in ssi4-induced developmental changes that require $S G T 1 b$ but not $R A R l$ and resemble those modulated by the phytohormone auxin.

\section{RESULTS}

\section{SGTIb but not RARI is necessary}

\section{for the ssi4-conditioned dwarf phenotype.}

To test whether RARI and SGTIb are required for ssi4-mediated signaling, ssi4 rarl and ssi4 sgtlb double mutants were generated by crossing ssi4 (Nö) with two null mutants, rarl-10 (Ler) and sgtlb-l (Ler), and selecting genetic combinations from segregating $\mathrm{F}_{2}$ populations using gene-specific polymerase chain reaction (PCR)-based markers (discussed below). Because the erecta (er) mutation in Ler affects plant morphology, morphological characterization was performed in two subgroups of mutants that contained either the $E R$ or er allele. When grown under standard conditions $\left(22^{\circ} \mathrm{C}\right.$ and 50 to $70 \%$ relative humidity $[\mathrm{RH}])$, the phenotype of ssi4 rarl ER plants, like that of ssi4 ER, was stunted. By contrast, ssi4 sgtlb ER double mutants were almost indistinguishable from SSI4 ER (Fig. 1A, B, and C). Measurement of the height of 4-week-old ER-containing double mutants revealed that ssi4 rarl ER plants were as stunted as ssi4 ER, whereas ssi4 sgtlb ER were only slightly smaller than SSI4 ER (Fig. 1D). Consistent with their respective sizes, the length and width of the fifth leaf of ssi4 rarl ER plants were as reduced as those of $s$ si4 ER, whereas the leaves on ssi4 sgtlb ER were nearly as large as those of SSI4 ER (Fig. 1D). In the er background, the size of ssi4 sgtlb er plants was indistinguishable from rarl er or $s g t l b$ er, whereas ssi4 rarl er plants were stunted and the length and width of their leaves dramatically reduced compared with rarl er or sgtlb er (Fig. $1 \mathrm{C}$; data not shown). Thus, sgt1b substantially suppresses ssi4induced stunting, whereas rarl does not. When ssi4 rarl ER plants were grown at HRH, a condition that suppresses all ssi4 (Nö) phenotypes (Zhou et al. 2004a), stunting was reversed (Fig. 1E), confirming that the dwarfism was due to the presence of ssi4.

\section{$R A R I$ but not $S G T 1 b$ is required for ssi4-induced $\mathrm{H}_{2} \mathrm{O}_{2}$ production and spontaneous cell death.}

In addition to their small stature, ssi4 plants developed spontaneous necrotic lesions on cotyledons and true leaves. Visual inspection of ssi4 rarl double mutants revealed that these plants did not form lesions although their leaves were chlorotic (Fig. 2A). By contrast, lesions were visible on fully expanded leaves of ssi4 sgt $1 b$ double mutants, although their appearance was delayed approximately 3 to 5 days compared with those on ssi4 plants. Lesion formation triggered by ssi4 was not affected by either $E R$ or $e r$. To determine whether spontaneous lesion formation was fully suppressed in ssi4 $\mathrm{rarl}$, cell death (monitored by trypan blue staining) and $\mathrm{H}_{2} \mathrm{O}_{2}$ production (by 3,3'-diaminobenzidine [DAB] staining) were examined microscopically. No cell death was detected in the leaves of rarl, sgt $1 b$, and ssi4 rarl mutants or the two wild type controls, SSI4 and Ler. By contrast, leaves of the ssi4 sgtlb double mutant and the ssi4 single mutant exhibited similar levels of cell death and $\mathrm{H}_{2} \mathrm{O}_{2}$ accumulation once necrotic lesions became visible (Fig. 2B and C). Based on these results, we concluded that $R A R 1$ is required for ssi4-mediated cell death, whereas $S G T 1 b$ is not.

In the course of these experiments, we found that low temperature $\left(16^{\circ} \mathrm{C}\right)$ induces ssi4-mediated cell death, SA accumulation, and $P R$ gene expression even when the plants are grown in HRH, which otherwise would suppress all ssi4 phenotypes (Fig. 2D and E; data not shown) (Zhou et al. 2004a). Low temperature combined with $\mathrm{HRH}$ failed to induce cell death in wild-type or ssi4 rarl plants but did so in ssi4 sgtlb (Fig. 2D and E). This finding further supports the conclusion that ssi4mediated cell death requires $R A R I$ but not $S G T 1 b$. Analysis of 10 independent lines for each double mutant over four generations revealed that the differences between ssi4 rarl and ssi4 $s g t 1 b$ phenotypes were robust and heritable.

\section{The stunted phenotype of ssi4 rarl is largely due to a reduction in cell number.}

The reduced stature of ssi4 and ssi4 rarl plants (Fig. 1) could be caused by a reduction in cell number, cell size, or both. To exclude distortions due to spontaneous cell death, mi- 
croscopic analysis was performed on wild-type (SSI4 RARI $E R$ ) and ssi4 rarl ER plants that, unlike the ssi4 single mutant, failed to form spontaneous lesions. Examination of the same square area of leaves from ssi4 rarl ER and wild-type plants revealed that the epidermis of ssi4 rarl ER double mutants contained slightly more cells that were smaller than those in the epidermis of wild-type leaves. In addition, the guard cells in ssi4 rarl ER were approximately $30 \%$ smaller than those in the wild type (Fig. 3A). This decrease in cell size is unlikely to account for the large difference in leaf size between wild-type and ssi4 rarl ER plants (Figs. 1 and 3A). Therefore, we investigated whether the number of cells in ssi4 rarl ER leaves was reduced by examining cross-sections of the stem at compara- ble locations. Analysis of ssi4 rarl ER stems revealed a dramatic reduction in cell number and a slight reduction in cell size compared with the wild type (Fig. 3B and C). Additionally, the stems of ssi4 rarl ER plants contained seven vascular bundles, whereas those of the wild type contained eight, and the number of cells in the primary phloem and xylem was dramatically reduced (Fig. 3B and C). Analysis of pollen grains in wild-type versus ssi4 rarl ER plants revealed that their size was comparable, but the number of pollen grains per anther was largely reduced (Fig. 3D; data not shown). Taken together, these results suggest that the dwarf phenotype of ssi4 rarl ER plants, and by extension ssi4 plants, results mainly from a reduction in cell number.
A
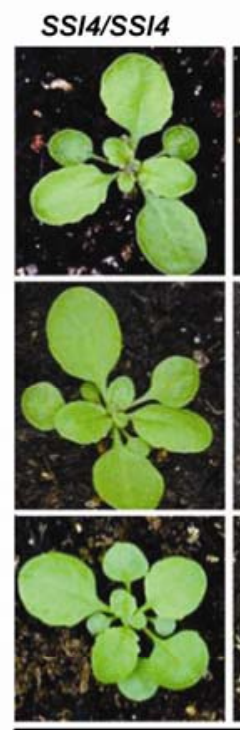

ss/4/ssi4
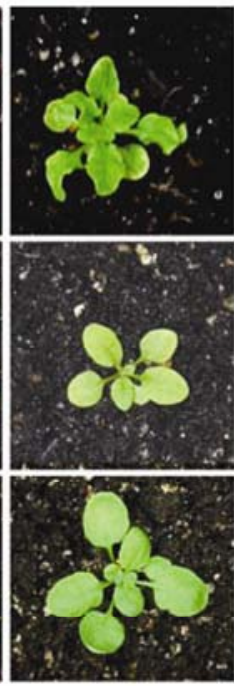

ER/ER

B

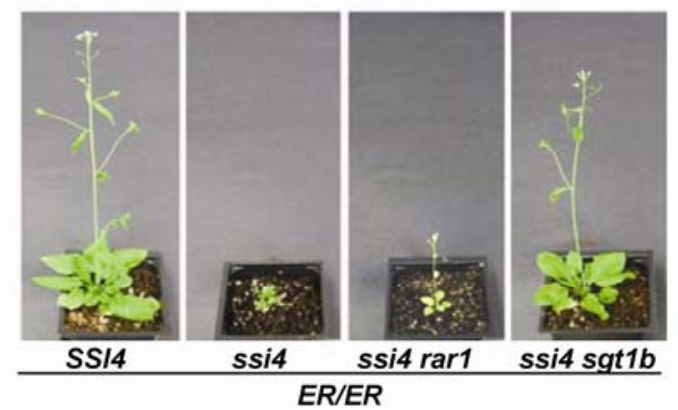

C

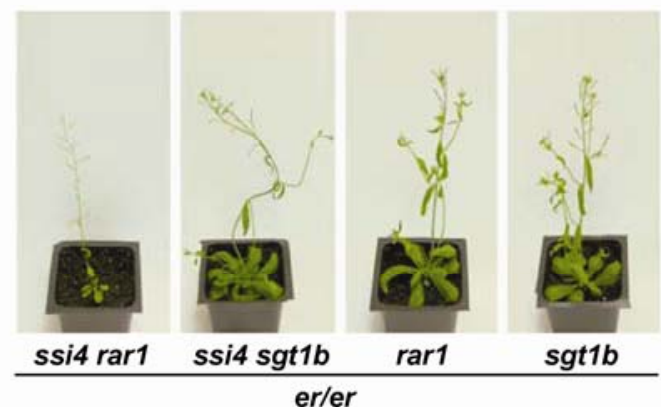

$s s i 4 / s s i 4$
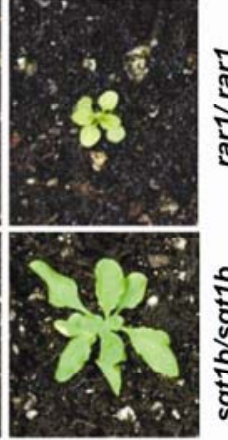
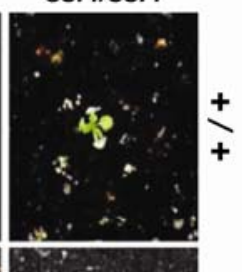

है
है
ถัฐ

कू

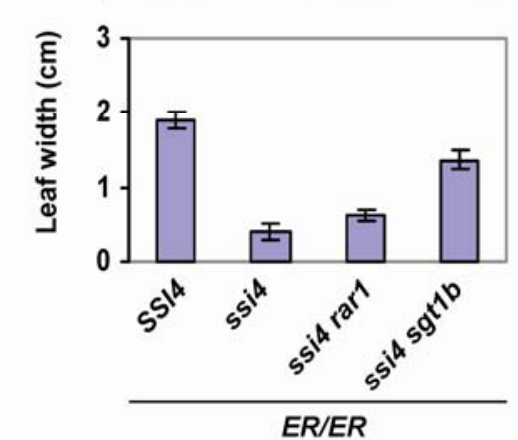

E

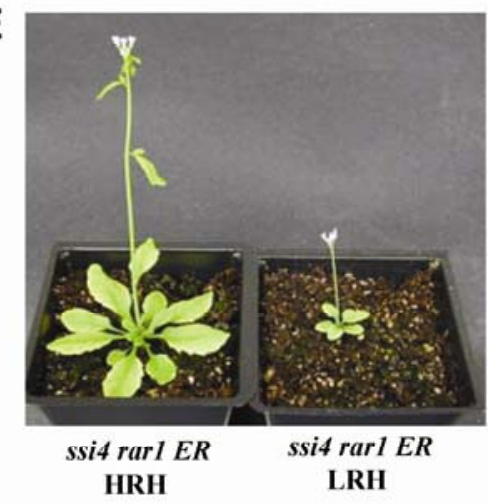

$E R / E R$
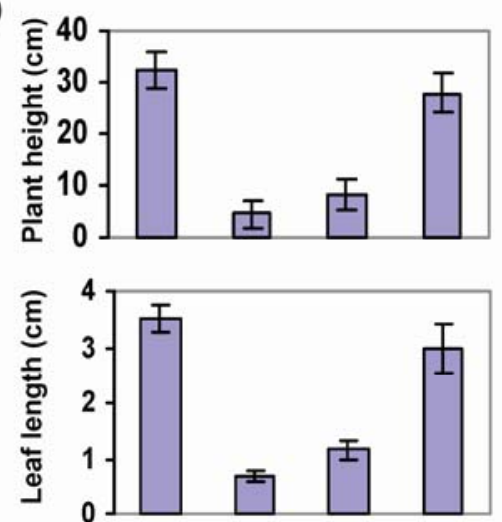

HRH

LRH

Fig. 1. Stunting induced by $s s i 4$ requires $S G T 1 b$ but not RAR1. A, Photographs of representative 4-week-old plants showing the effect of rarl or $s g t 1 b$ on the morphology of ssi4 or SSI4 plants containing the ER allele. The ssi4 rarl ER plants were as stunted as ssi4 ER plants, although their leaves were lighter green, and ssi4 sgt 1 b ER plants were nearly the same in size as $S S I 4$ ER, but retained wrinkled leaves. All plants were from $\mathrm{F}_{2}$ populations. B, Representative $S S I 4$, ssi4, ssi4 rarl, and ssi4 sgtlb plants in the ER background were from $\mathrm{F}_{2}$ populations and photographed at 8 weeks of age. C, Representative ssi4 rarl, ssi4 sgt1b, rarl, and sgtlb plants in er background were from $\mathrm{F}_{2}$ populations and photographed at 8 weeks of age. D, Quantitative measurement of the height of 12-week-old plants as well as the length and width of their fifth leaves at 4 weeks of age. The histogram represents the mean \pm standard deviation of 20 plants for each genotype with the same genetic background as in B. E, Representative plants of ssi4 rarl ER grown in high relative humidity (HRH) (95\%) or moderate RH (60\%), showing that HRH suppresses the dwarf phenotype of ssi4 rarl ER but does not change leaf color. 
The ssi4 rarl sgt1b mutant displays hypersusceptibility to an oomycete pathogen.

We assessed whether $R A R I$ and $S G T 1 b$ play roles in ssi4-mediated resistance to Hyaloperonospora parasitica isolate EMCO5, a pathogen that is virulent on wild-type (Nö) plants but avirulent on ssi4 (Nö) (Shirano et al. 2002). Because Ler plants contain the RPP8 gene which confers RARI- and SGTIbindependent resistance to EMCO5 (Muskett and Parker 2003), we used a cleaved amplified polymorphic sequence (CAPS) marker for RPP8 to select ssi4 rarl and ssi4 sgtlb double mutants that did not carry RPP8. Three ssi4 rarl and three ssi4 $s g t l b$ lines without RPP8 were inoculated with EMCO5. Microscopic analysis of 10-day-old and 4-week-old plants revealed that ssi4 rarl and ssi4 sgtlb double mutants supported similar levels of hyphal growth and sporangiophore development that were significantly greater than the levels observed on comparable ssi4 single mutants but lower than those exhibited by SSI4 plants (Fig. 4A and B). The 10-day-old and 4-week-old plants of the ssi4 rarl and ssi4 sgtlb double-mutant lines also developed similar levels of host cell death after infection, although this response was less severe than that of similarly inoculated ssi4 single mutants (Fig. 4C). By contrast, no host cell death was detected in SSI4 plants at 7 days after infection.
To assess whether the suppressive effect of rarl or $s g t l b$ on ssi4-mediated resistance is additive, we generated ssi4 rarl $s g t l b$ triple mutant lines in an RPP8-deficient background by crossing susceptible ssi4 rarl and ssi4 sgtlb double mutants and genotyping the progeny using rarl-and sgtlb-specific PCR markers. The triple mutants were morphologically indistinguishable from SSI4 plants. Both dwarfism and necrotic lesion phenotypes caused by ssi4 were completely suppressed. Analysis of ssi4 rarl sgtlb triple mutant lines in response to EMCO5 inoculation revealed that these were substantially more susceptible to the pathogen than either double-mutant line. The triple mutants supported more than twofold greater sporangiophore development than SSI4 plants and failed to develop an HR (Fig. 4B and C). The extreme susceptibility of ssi4 rarl sgtlb plants suggests that RARl and $S G T 1 b$ are needed not only for ssi4-mediated resistance but also for basal resistance to virulent pathogens.

\section{ssi4-induced SA accumulation}

and defense gene expression require $R A R 1$ and $S G T 1 b$.

Previously, it was demonstrated that ssi4 accumulates elevated levels of the defense signaling hormone SA and constitutively expresses several classes of defense genes (Zhou et al. 2004a).
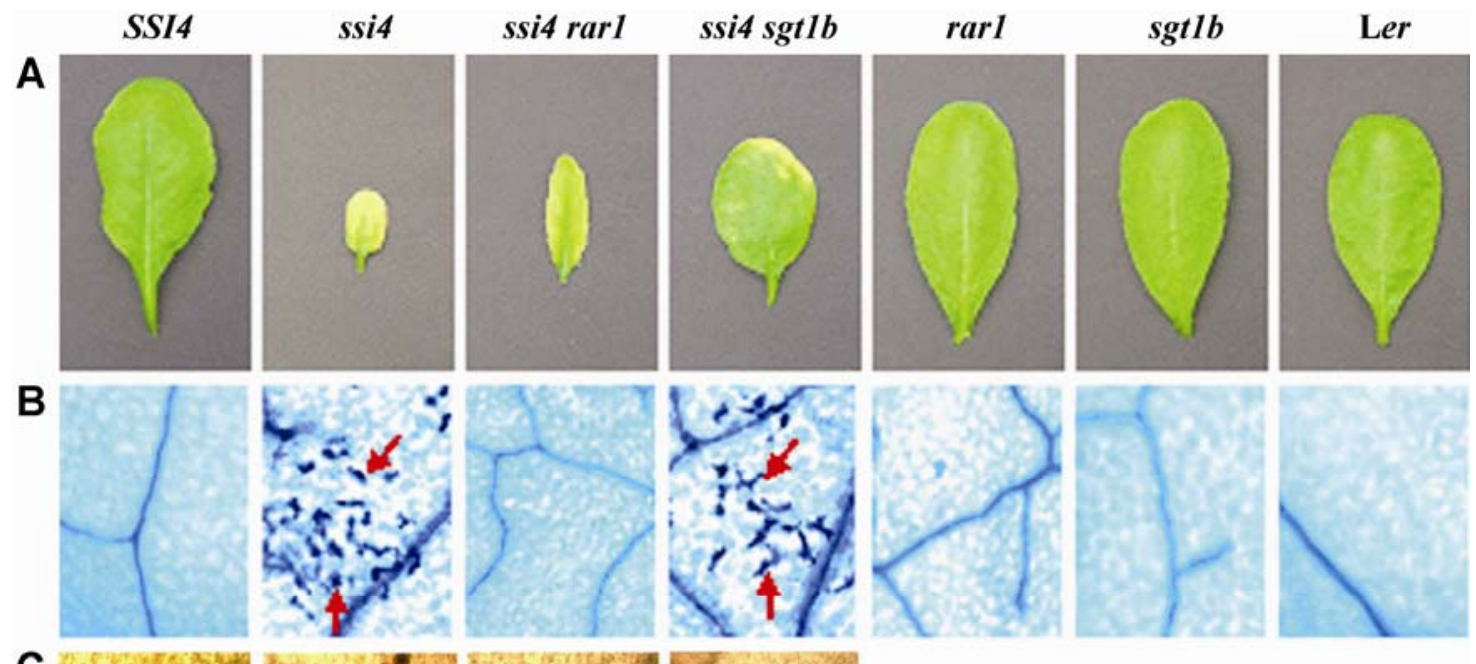

C
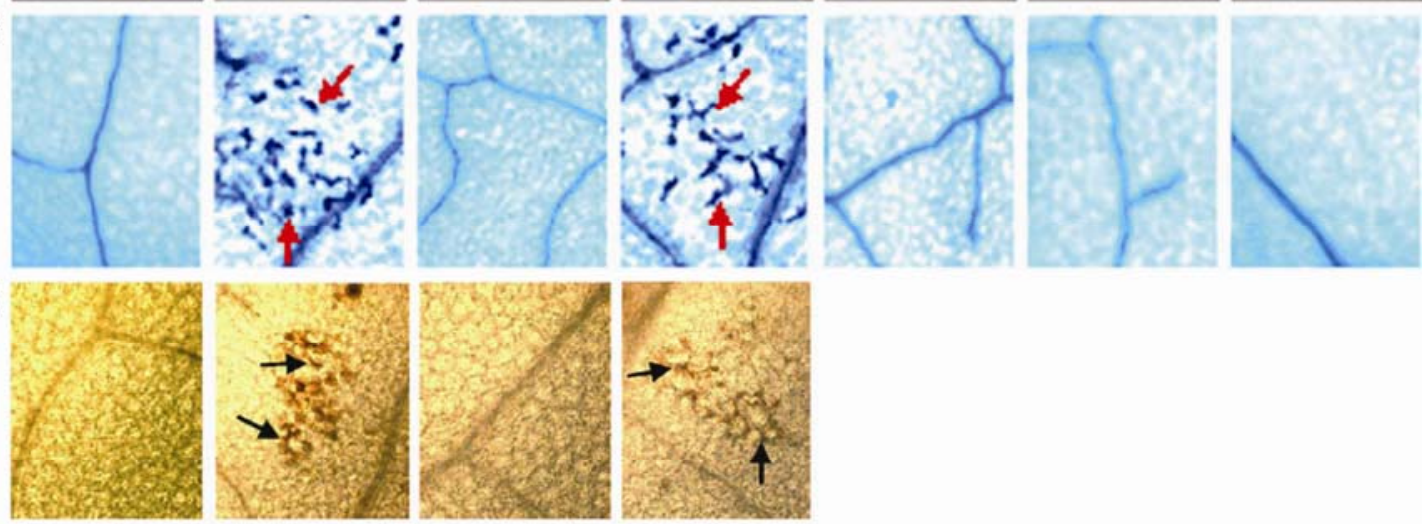

D
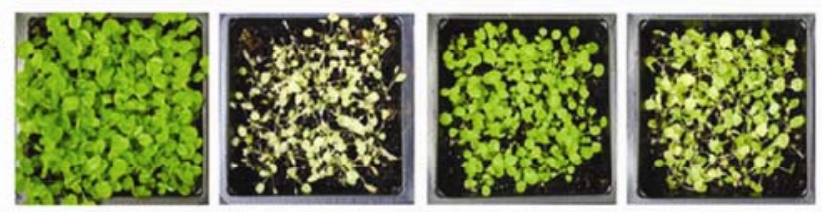

E
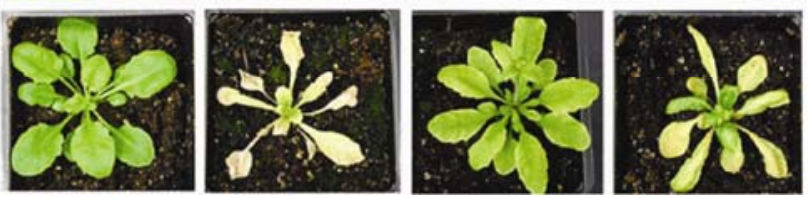

Fig. 2. $\mathrm{H}_{2} \mathrm{O}_{2}$ production and spontaneous cell death in SSI4, ssi4, and the ssi4 rarl and ssi4 sgtlb double mutants. A, The fifth leaf of 4-week-old plants grown under moderate relative humidity $(\mathrm{RH})(60 \%)$ at $22^{\circ} \mathrm{C}$ was photographed. Note the necrotic lesions on leaves from $s s i 4$ and $s s i 4 s g t 1 b$ plants but not ssit rarl, although the latter had yellowish leaf color. All plants, except for Ler, were $\mathrm{F}_{2}$ population. B, Trypan blue staining of similar leaves as in A revealed mesophyll cell death in ssi4 and ssi4 sgt $1 \mathrm{~b}$ plants, as indicated by arrows. $\mathbf{C}, 3,3^{\prime}$-Diaminobenzidine staining of similar leaves as in $\mathrm{A}_{\text {revealed }} \mathrm{H}_{2} \mathrm{O}_{2}$ accumulation in ssi4 and ssi4 sgtlb plants, as indicated by the dark-brown regions noted by arrows. D, Ten-day-old plants grown in high relative humidity (HRH) $(95 \%)$ conditions at $22^{\circ} \mathrm{C}$ were shifted to $16^{\circ} \mathrm{C}$ at $\mathrm{HRH}$ and photographed 5 days after the temperature shift. E, Six-week-old plants were shifted from $22^{\circ} \mathrm{C}$ at $\mathrm{HRH}$ to $16^{\circ} \mathrm{C}$ at $\mathrm{HRH}$ and photographed 5 days after the temperature shift. 
To assess whether the rarl or sgtlb mutations affect these ssi4induced responses, SA levels were monitored in ssi4 rarl and ssi4 sgtlb double mutants, an ssi4 rarl sgtlb triple mutant, and parental lines. As expected, ssi4 single mutants accumulated approximately 18 -fold more SA and approximately 90 -fold more SA glucoside (SAG) than wild-type plants, SSI4 (Nö), or SSI4 (Ler) (Fig. 5A and B). SA and SAG levels were substantially reduced in ssi4 sgtlb double mutants, although they were still 5and 15-fold greater than the levels in the wild type, respectively. Even lower levels of SA and SAG were observed in ssi4 rarl double mutants, although these also were elevated (approximately three- and sixfold, respectively) over wild-type plants. By contrast, SA and SAG levels in the ssi4 rarl sgtlb triple mutant were similar to the wild type. Analysis of rarl and $s g t 1 b$ single and double mutants in the SSI4 background revealed no change in SA or SAG levels compared with wild-type Ler.

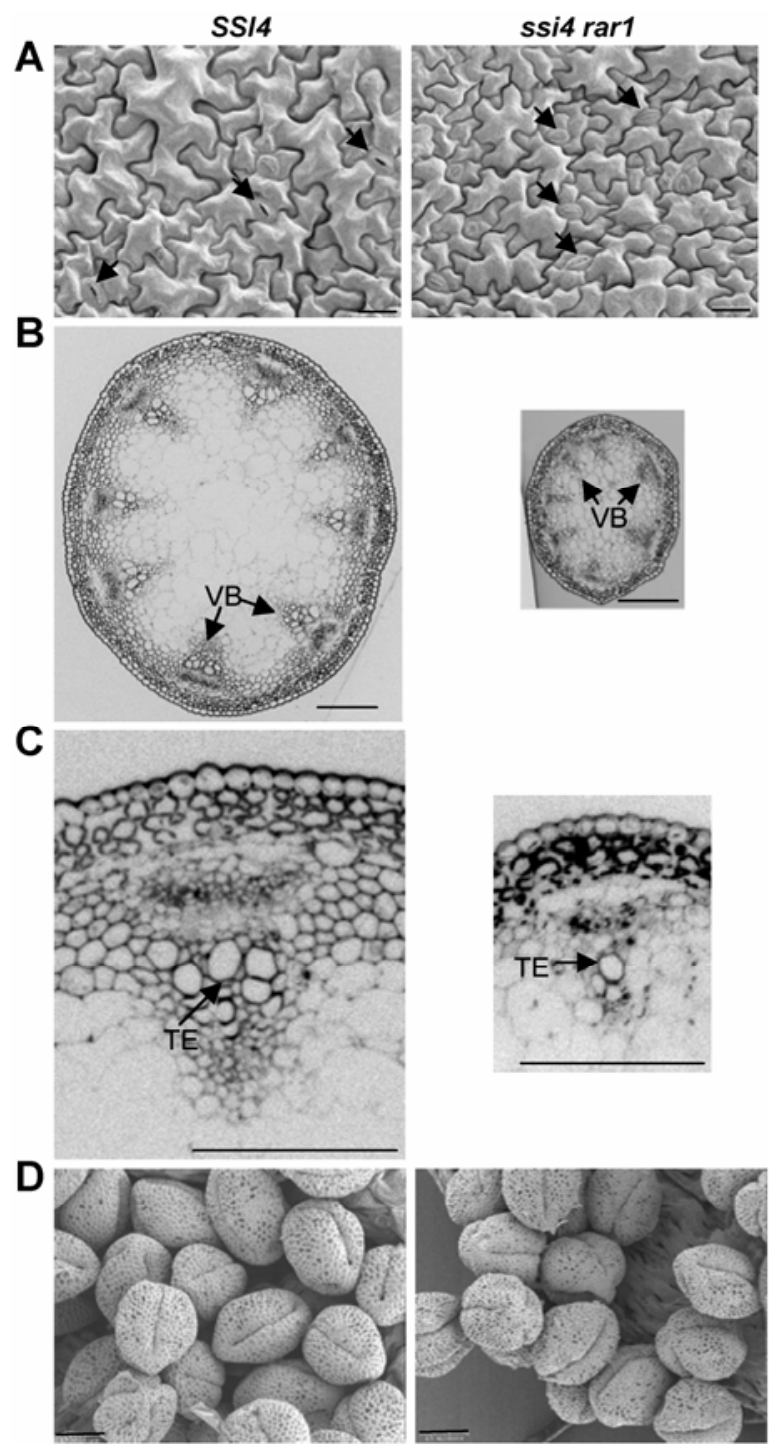

Fig. 3. Anatomical characteristics of cell morphology in different organs of wild-type and ssi4 rarl ER plants. A, Scanning electron microscopic images of the epidermal cells of rosette leaves from 4-week-old SSI4 RARI ER and ssi 4 rarl ER plants. The bar represents $20 \mu \mathrm{m}$ and the arrows point to stomata. B, Light microscopic images of a cross section of the stem at the second internode from the bottom of 8-week-old SSI4 RARI ER and ssi4 rarl $E R$ plants. The bar represents $100 \mu \mathrm{m}$ and VB = vascular bundle. C, Closeup view of the stem cross sections showing epidermal cells and a vascular bundle. The bar represents $100 \mu \mathrm{m}$ and TE $=$ tracheary element. D, Scanning electron microscopic images of pollen grains from SSI4 RARI ER and ssi4 rarl ER plants. The bar represents $10 \mu \mathrm{m}$.
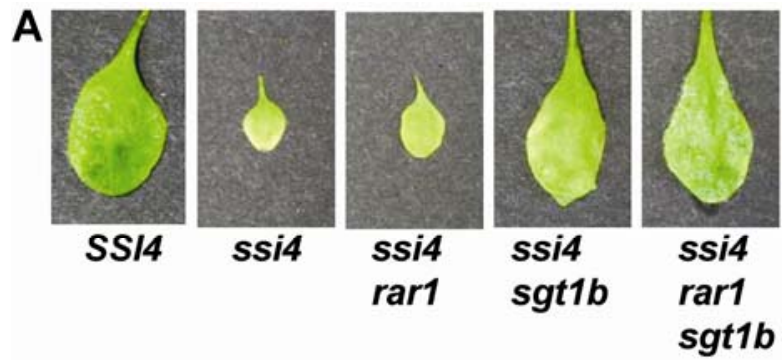

B

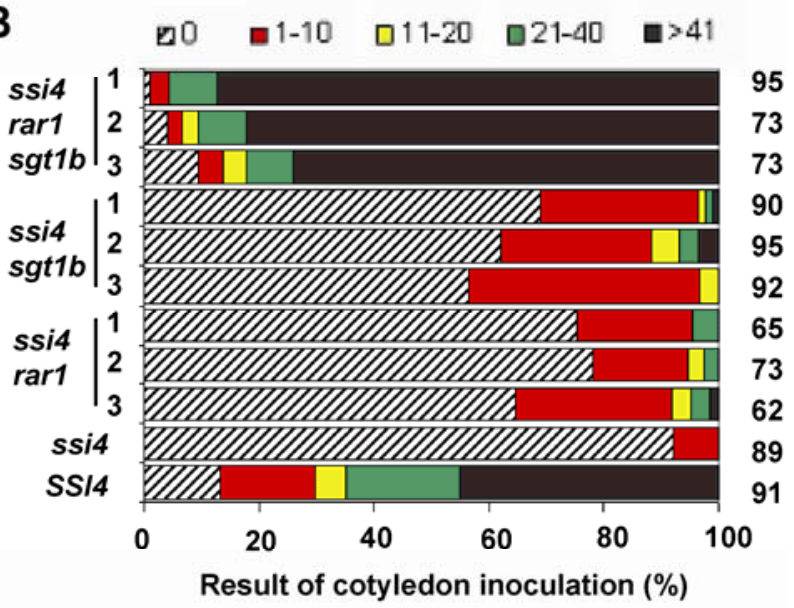

C
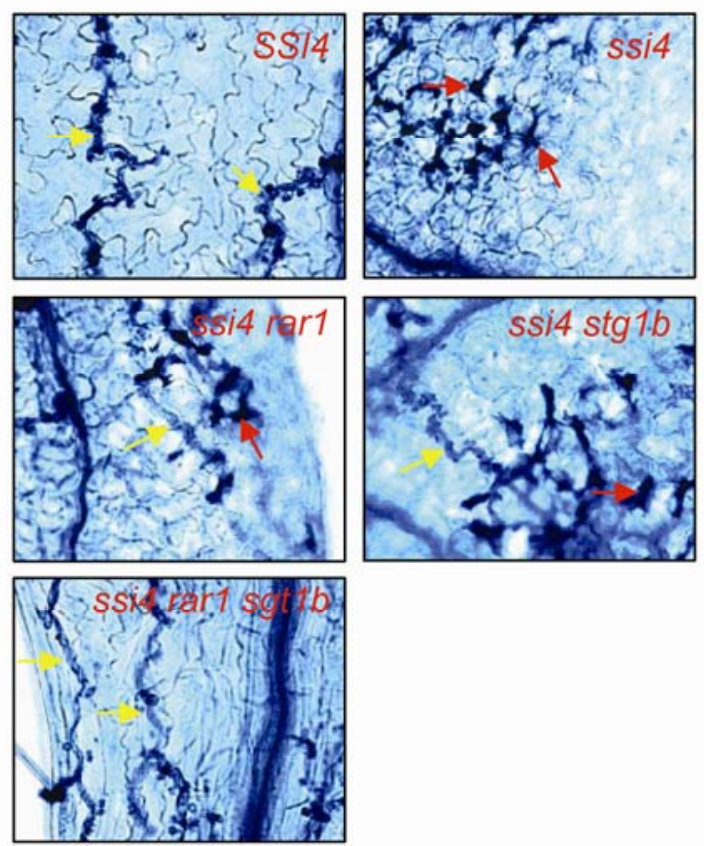

Fig. 4. $R A R I$ and $S G T I b$ function synergistically to mediate $s s i 4$-induced resistance to Hyaloperonospora parasitica. A, Plants (4 weeks old) of various genotypes from $\mathrm{F}_{3}$ lines were spray inoculated with $H$. parasitica EMCO5 (10 5 spores $/ \mathrm{ml})$. At 7 days postinoculation (dpi), representative leaves were photographed. B, Resistance to $H$. parasitica EMCO5 was quantitated in SSI4 plants and in ssi4 single, double, and triple mutants by counting the number of sporangiophores on cotyledons of 10-day-old seedlings collected at $7 \mathrm{dpi}$. The cotyledons were grouped into five categories based on the number of sporangiophores detected. The percentage of each category was calculated based on examination of approximately 60 to 100 cotyledons (the number examined is shown to the right of each bar). C, Trypan blue staining of infected cotyledons to reveal hyphal growth (as indicated by yellow arrows) and mesophyll cell death (as indicated by red arrows). Please note that the hyphae have normal morphology. However, in order to capture the hyphae and dead host cells in the same view, the hyphae or dead host cells are somewhat out of focus and, therefore, hyphae beads-on-a-string morphology is not apparent. 
To investigate the correlation between SA accumulation and defense gene expression, $P R-1$ transcript levels were monitored by RNA gel blot analysis in all genotypes used for SA measurements. The ssi4-induced $P R-1$ expression was reduced substantially in the presence of rarl or $s g t l b$, although $P R-1$ transcript levels in ssi4 sgtlb were higher than in wild-type plants (Fig. 5C). RNA gel blot analysis of additional defense genes, including PR-2, PR-5, RPW8.1 RPW8.2, WRKY6, WRKY29, and $E D S 1$, similarly revealed that their ssi4-induced expression was reduced or fully suppressed by the loss of $R A R I$ and/or $S G T 1 b$ (Fig. 5D). Mutations in either RARl or $S G T 1 b$ substantially reduce ssi4-induced SA accumulation and defense gene expression; therefore, we concluded that both genes are required for full activation of these responses in the ssi4 mutant.

\section{DISCUSSION}

Previous studies have demonstrated that RARI and $S G T 1 b$ are required for disease resistance mediated by various plant $R$ genes in response to corresponding pathogen effectors (Austin et al. 2002; Azevedo et al. 2002; Holt et al. 2005; Liu et al. 2002a; Muskett et al. 2002; Shirasu et al. 1999; Tör et al. 2002; Tornero et al. 2002). Here, we show that RARl and $S G T 1 b$ are as important for defense activation and developmental alterations conditioned by a deregulated NB-LRR protein, ssi4. Thus, ssi4 (behaving as activated TIR-NB-LRR protein) cannot override many $s g t l b$ and rarl defects that are associated with the regulation of properly constrained NB-LRR receptors. Although SGT1b and RARl have cooperative functions in ssi4induced pathogen resistance, they have distinct roles in conditioning developmental changes and triggering cell death, respectively (Figs. 2 and 3). These findings raise the question of whether RAR1 and SGT1 are needed only in the assembly of preexisting NB-LRR complexes or have broader functions during NB-LRR activation or downstream signaling. It is likely that a certain threshold of ssi4 protein needs to be attained to induce constitutive resistance, as is the case for authentically activated plant NB-LRR receptors (Azevedo et al. 2002; Bieri
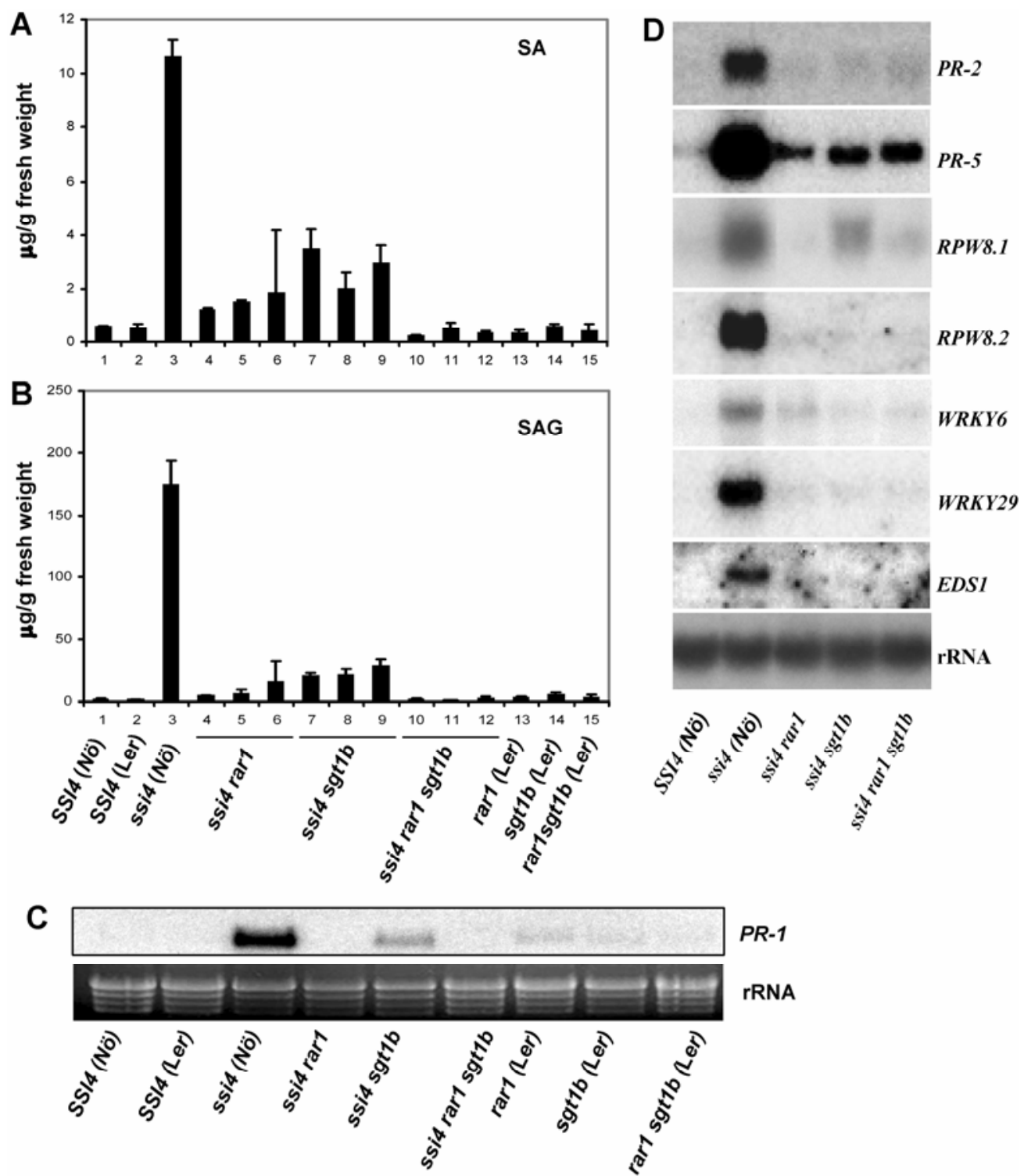

$P R-1$

rRNA

Fig. 5. Salicylic acid (SA) accumulation and defense gene expression in wild-type and ssi4 single, double, and triple mutants. A, Free SA content in 4-weekold plants grown in moderate relative humidity $(\mathrm{RH})(60 \%)$. The histogram represents the mean \pm standard deviation (SD) of four independent samples. Three different lines were analyzed for the double and triple mutants. B, The SA glucoside (SAG) content in the same tissue as in A. The histogram represents the mean \pm SD of four independent samples. C, Northern analysis of $P R-1$ transcripts in wild-type and mutant lines grown at $60 \%$ RH; $10 \mu \mathrm{g}$ of total RNA was loaded on each lane and ethidium bromide-stained rRNA was used as a control for loading. D, Northern analysis of transcripts for several defense genes in wild-type and mutant lines grown at $60 \% \mathrm{RH} ; 10 \mu \mathrm{g}$ of total RNA was loaded on each lane and rRNA was used as a control for loading. 
et al. 2004; Holt et al. 2005). The observation that ssi4 is a semi-dominant mutation is consistent with a threshold model (Azevedo et al. 2006) and, therefore, both RAR1 and SGT1 may assist ssi4 protein assembly. High levels of ssi4 transcripts detected in ssi4 homozygous plants (Shirano et al. 2002) may explain why ssi4-mediated resistance is only partially dependent on $R A R 1$. An alternative explanation is that RAR1 or SGT1 function after NB-LRR protein activation. Activities of RAR1 and SGT1b at different points of ssi4-conditioned signaling could account for the uncoupling of rarl and $s g t l b$ phenotypes observed in this study. The differential recruitment of $S G T 1 b$ in conditioning developmental alterations and $R A R l$ in triggering cell death is more difficult to explain by quantitative differences in ssi4 protein accumulation in these mutants. In transient $N$. benthamiana expression assays, SGT1 was necessary to generate intramolecular folding intermediates of the pepper Bs2 NB-LRR protein that may be important for receptor activation (Leister et al. 2005). It also is notable that analyses of two mammalian NB-LRR receptors, Nod1 and Nod2, suggest a role of SGT1 in receptor signaling leading to the activation of downstream immune responses (da Silva Correia et al. 2007; Mayor et al. 2007).

Both $S G T 1 b$ and RARI were required for ssi4-mediated resistance to $H$. parasitica isolate EMCO5, as well as for pathogen-induced HR development, SA accumulation, and defense gene expression. Loss of $S G T 1 b$ or RARI in the ssi4 background diminished all these responses (with the exception of defense gene expression) to a level that was intermediate between that observed in ssi4 single mutants and ssi4 sgtlb rarl triple-mutant plants. Thus, RAR1 and SGT1b appear to have distinct activities that work cooperatively to activate most ssi4induced defense responses. Genetic analyses in Arabidopsis and barley suggested that $R A R I$ and $S G T 1$ also work cooperatively to signal $R P P 5$-mediated resistance to $H$. parasitica isolate Noco2 and Mla6-mediated resistance to powdery mildew (Austin et al. 2002; Azevedo et al. 2002). In addition to mediating $R$ gene-triggered defenses, our results show that $R A R I$ and $S G T 1 b$ are required for basal resistance to a virulent $H$. parasitica (Fig. 4). In contrast to wild-type SSI4 plants that are susceptible to EMCO5 and display high levels of sporangiophores on approximately $45 \%$ of their cotyledons, ssi4 rarl sgtlb triple mutants were hypersusceptible, supporting highlevel sporulation on approximately $80 \%$ of their cotyledons (Fig. 4). Previous analyses of rarl sgtl double mutants in Arabidopsis did not detect enhanced susceptibility over that associated with loss of the corresponding $R$ gene (Austin et al. 2002; Azevedo et al. 2002; Holt et al. 2005). However, hypersusceptibility to a virulent bacterial pathogen was observed in rarl single-mutant Arabidopsis (Holt et al. 2005). Also, silencing of SGT1 in N. benthamiana led to increased replication of TMV and Potato virus $X$ over that detected in plants silenced for either $N$ or $R x$, respectively, and abolished nonhost resistance to certain bacterial pathogens (Peart et al. 2002). Those findings, combined with our results, implicate RAR1 or SGT1 in the regulation of basal, race-specific, and nonhost resistance consistent with these responses having at least some signaling mechanisms in common. Alternatively, instability of NB-LRR proteins in rarl or $s g t l b$ mutants as described earlier (Azevedo et al. 2002; Bieri et al. 2004; Holt et al. 2005) may account for the various forms of enhanced susceptibility in these mutants if different NB-LRR proteins are involved in basal, race-specific, or nonhost resistance.

Although both SGT1 and RAR1 are required for $R$ genemediated and basal resistance, they appear to work separately to condition other ssi4-induced morphological alterations. Importantly, ssi4-induced stunting requires SGT1b but not RAR1. Analysis of stem cross-sections and pollen grains from ssi4 rarl plants suggested that the stunted phenotype is largely due to a reduction in cell number. The reduced vasculature in these plants is reminiscent of the vascular defects displayed by auxin-deficient tobacco expressing a 35S-iaaL construct, which encodes an indoleacetic acid (IAA)-lysine synthetase that converts IAA to IAA-lysine (Romano et al. 1991). SGT1b previously was shown to be required for $\mathrm{SCF}^{\mathrm{TIR} 1}$, a ubiquitin protein ligase that functions as a key regulator of the auxin response in Arabidopsis (Gray et al. 2003). Thus, SGT1b may mediate ssi4-induced stunting by altering auxin signaling.

By contrast, ssi4-induced spontaneous cell death was abolished in the absence of RARl but not $S G T 1 b$. However, spontaneous lesion formation was delayed by several days in ssi4 $s g t l b$ mutants compared with ssi4 plants, suggesting that SGTIb influences the timing of cell death. Other studies revealed activities of RAR1 or SGT1 in $R$ gene-mediated HR development after pathogen infection (Austin et al. 2002; Freialdenhoven et al. 1994; Holt et al. 2005; Muskett et al. 2002; Peart et al. 2002; Shirasu et al. 1999; Tornero et al. 2002). Because spontaneous cell death shares many characteristics with pathogeninduced HR (Dietrich et al. 1994), both phenomena are thought to be activated via the same signaling pathway. The discovery that RARl is indispensable for ssi4-induced spontaneous cell death but a quantitative factor in pathogen-induced HR development could be explained by the fact that they are different processes or, more likely, that they are influenced by the extent of accumulation and competence of the NB-LRR protein involved.

Constitutive activation of defense responses frequently causes two closely associated phenotypes: spontaneous cell death leading to necrotic lesion formation and inhibition of growth resulting in a dwarfism. These have been described in several Arabidopsis mutants, such as cpr22, ssi2, cpn1/bon1, and others (Hua et al. 2001; Jambunathan et al. 2001; Kachroo et al. 2001; Yoshioka et al. 2001). The generation of a large quantity of reactive oxygen species (ROS), know as oxidative burst, is an early event in $R$ gene-mediated defense signaling which was believed to trigger necrotic lesion formation and a dwarf phenotype. Consistent with this, we found that growth of ssi4 under HRH conditions abrogated not only $\mathrm{H}_{2} \mathrm{O}_{2}$ accumulation but also lesion formation and dwarfism (Zhou et al. 2004a). One explanation is that the toxic effect of ROS causes cell death and growth inhibition. However, such a scenario recently has been ruled out in the flu mutant by the identification of a suppressor, executerl (Wagner et al. 2004), which reverses flu-mediated cell death and dwarfism but did not suppress singlet oxygen production. This result suggests that flu triggers cell death and dwarfism by activation of an intrinsic signaling pathway involving EXECUTERI rather than via the direct damaging effect of ROS. Because both dwarfism and cell death in flu are suppressed by executerl, researchers were unable to separate the two phenotypes. In this study, we separated ssi4-mediated cell death from its dwarf phenotype by introducing rarl or $s g t l b$ into the ssi4 background. Analyses of ssi4 rarl and ssi4 sgtlb revealed that ssi4 triggers necrotic lesion formation and dwarfism through two distinct signaling pathways or branches, which require Rarl and $S g t 1 b$, respectively. The ssi4-mediated signaling via $S G T 1 b$ leads to dwarfism, whereas signaling via $R A R l$ triggers lesion formation.

$\mathrm{H}_{2} \mathrm{O}_{2}$ accumulation prior to lesion formation in ssi4 sgtlb suggests that $\mathrm{H}_{2} \mathrm{O}_{2}$ may be a signaling component for ssi4-triggered cell death. This is consistent with suppression of both $\mathrm{H}_{2} \mathrm{O}_{2}$ accumulation and cell death in ssi4 rarl. In contrast, retention of the dwarf phenotype in ssi4 rarl argues that $\mathrm{H}_{2} \mathrm{O}_{2}$ accumulation is not involved in triggering dwarfism. However, it is possible that a small, not readily detectable, increase in $\mathrm{H}_{2} \mathrm{O}_{2}$ in ssi4 rarl leads to dwarfism. 
Previous analysis revealed that all ssi4 phenotypes are completely suppressed by high-humidity conditions, and an HSF was proposed to regulate an early step in the ssi4 pathway (Zhou et al. 2004a). Here, we demonstrate that ssi4-induced spontaneous cell death, SA accumulation, and $P R$ gene expression are triggered by low temperature (LT) even in plants grown under HRH conditions. LT-induced spontaneous cell death required $R A R 1$, although the presence of $S G T 1 b$ influenced the timing. Thus, LT appears to activate ssi4-induced spontaneous cell death via the same pathway as in plants grown at normal temperatures, possibly by restoring HSF activity. High humidity suppresses constitutive resistance activated by other mutations, as well as $R$ gene-induced defenses in Arabidopsis and tomato, consistent with the notion that these pathways all are regulated by one or more HSFs (Hammond-Kosack et al. 1996; Jambunathan et al. 2001; May et al. 1996; Weymann et al. 1995; Xiao et al. 2003; Yoshioka et al. 2001). Strikingly, high-humidity suppression of the cpn1/bonl induced spontaneous lesion formation; enhanced disease resistance, constitutive $P R$ gene expression, and stunting; and was overridden by LT (Jambunathan and McNellis 2003; Yang and Hua 2004). CPN1/BON1 is a negative regulator of SNC1, a homolog of the TIR-NB-LRR R protein RPP5 (Yang and Hua 2004; Zhang et al. 2003). Thus, the constitutive activation of defense responses in cpn1/bonl plants, like that in ssi4 plants, is caused by deregulated activity of an $\mathrm{R}$ protein. $\mathrm{HRH}$ conditions also suppress resistance and spontaneous lesion formation conferred by overexpression of the powdery mildew resistance genes $R P W 8.1$ and $R P W 8.2$ (Xiao et al. 2003). These genes encode small, basic proteins with a putative $\mathrm{N}$-terminal transmembrane domain and a CC domain but no NB or LRR. Although the effect of LT on the RPW8.1 and $R P W 8.2$ overexpression phenotype is not known, transcripts for these genes accumulate to high levels in the ssi4 mutant in a humidity-sensitive manner (Zhou et al. 2004a). Establishing that the ssi4, SNC1, RPW8.1, and RPW8.2 signaling pathways are dependent on SA and EDS1 and that their corresponding $R$ genes are positively regulated by SA via a feedback loop (Li et al. 2001; Shirano et al. 2002; Xiao et al. 2003; Yang and Hua 2004) suggests that a common mechanism underlies environmental control of these defense pathways.

\section{MATERIALS AND METHODS}

Plant materials and growth conditions.

Arabidopsis rarl-10 and sgt $1 b-1$ mutants (Ler background) were described previously (Austin et al. 2002, Muskett et al. 2002). To generate ssi4 rarl and ssi4 sgtlb double mutants, ssi4 (Nössen [Nö] background) was crossed reciprocally with rarl-10 and sgtlb-1; ssi4 also was crossed with Ler as a control. $\mathrm{F}_{1}$ plants in all crosses showed a phenotype similar to heterozygous $S S I 4 /$ ssi4 plants. $\mathrm{F}_{2}$ progeny were genotyped using CAPS markers specifically designed for ssi4, rarl-10, or sgtlb (Austin et al. 2002; Muskett et al. 2002; Shirano et al. 2002). To screen for the loss of RPP8 in ssi4 rarl, ssi4 sgtlb, and ssi4 rarl sgtlb plants, an approximately 375-bp fragment was amplified using the forward primer 5'-ACGAACATATAACCT GATGATTCAC-3' and the reverse primer 5'-CTTAGATTAGC TCATGATCTTATAC-3' and digested with Fnu4HI. This generated either a 375-bp undigested fragment in the amplified product from Ler RPP8 or 300- and 75-bp fragments in the amplified product from Nö plants. Homozygous ssi4 rarl and ssi4 sgtlb double mutants were identified from the $\mathrm{F}_{2}$ populations and further divided into two subgroups containing the $E R$ or er allele based on characteristic morphology alterations. Over 10 independent individual lines of each double mutant, ssi4 rarl ER and ssi4 sgtlb ER, were screened for the absence of $R P P 8$, and three lines of each double mutant without RPP 8 were selected for disease resistance analysis. To generate ssi4 rarl sgtlb triple-mutant lines, ssi4 rarl rpp8 and ssi4 sgtlb rpp 8 plants were crossed and CAPS markers were used to screen for the homozygous triple mutant. Characterization was performed using $\mathrm{F}_{4}$ homozygous mutant lines. All plants were grown in growth chambers set for $100 \mu \mathrm{mol} \mathrm{m}{ }^{-2} \cdot \mathrm{s}^{-1}$ light intensity, light and dark periods of 14 and $10 \mathrm{~h}$, respectively, $22^{\circ} \mathrm{C}$, and moderate $\mathrm{RH}$ of $60 \%$, except for the humidity shift experiments, where $\mathrm{HRH}$ was set at $95 \%$, and for the temperature shift experiments, where low temperature was set at $16^{\circ} \mathrm{C}$.

\section{Plant anatomical analysis.}

For scanning electron microscopy, 2-by-3-mm pieces were taken from the fully expanded fifth leaf of 4-week-old plants and immediately fixed in $2.5 \%$ glutaraldehyde in $0.1 \mathrm{M}$ sodium cacodylate buffer, $\mathrm{pH}$ 6.8. Entire flowers were collected just before opening and fixed in the same solution. After an overnight incubation in the fixative at $4^{\circ} \mathrm{C}$, the specimens were rinsed in cold buffer ( $0.1 \mathrm{M}$ sodium cacodylate buffer, $\mathrm{pH} 6.8$ ) 3 times for $10 \mathrm{~min}$ each, then transferred to $2 \%$ osmium tetraoxide and kept at $4^{\circ} \mathrm{C}$ overnight. Cold water was used to rinse the specimens three times for $10 \mathrm{~min}$ each. After dehydration in an ethanol series $(10,30,50,70$ plus $2 \%$ uranyl acetate, 90, and 100\%), specimens were dried using Balzers CPD 030 critical point dryer (Balzers Union, Furstentum, Liechtenstein). The dried specimens were mounted on an aluminum stub with double-sided tape. Approximately $45 \mathrm{~nm}$ of gold/palladium was coated onto the specimens in Balzers scd 050 sputter coater (Balzers Union, Liechtenstein). Selected specimens were examined and photographed using a Hitachi S4500 Scanning Electron Microscope (Hitachi High Technologies America Inc., Pleasanton, CA, U.S.A.).

For light microscopy, the same procedures were followed as described by Zhou and associates (2000). The sections were stained with Azure B.

\section{DAB and trypan blue staining.}

To monitor $\mathrm{H}_{2} \mathrm{O}_{2}$ accumulation in situ, DAB (Sigma-Aldrich, St. Louis) staining was performed according to ThordalChristensen and associates (1997), with modifications. The fifth leaf was detached from 4-week-old plants and put in an Eppendorf tube containing $1 \mathrm{ml}$ of DAB solution with the leaf petiole being submerged. DAB solution was taken up by the leaf through transpiration. After $6 \mathrm{~h}$ of treatment, the leaf was cleared by boiling in ethanol/lactic acid/glycerol (4:1:1) for 5 min. For microscopy and photography, the cleared leaf segments were mounted on glass slides in $30 \%$ glycerol. Representative images were taken using a digital camera (FIH033947; Olympus, Goleta, CA, U.S.A.) adapted to the microscope (Axioskop; Zeiss, Oberkochen, Germany). To visualize cell death and fungal growth in mesophyll tissue, whole leaf samples were collected from pathogen-infected plants at 7 days postinoculation, stained with trypan blue solution $(10 \mathrm{ml}$ of lactic acid, $10 \mathrm{ml}$ of glycerol, $10 \mathrm{~g}$ of phenol, and $10 \mathrm{mg}$ of trypan blue dissolved in $10 \mathrm{ml}$ of distilled water) by boiling for approximately $1 \mathrm{~min}$, and then cleared in chloral hydrate $(2.5 \mathrm{~g}$ of chloral hydrate dissolved in $1 \mathrm{ml}$ of distilled water). They were mounted in chloral hydrate and examined under a light microscope as described above.

\section{RNA isolation and Northern blot analysis.}

Total RNA was isolated from Arabidopsis leaf tissues using TRIzol reagent (Life Technologies, Rockville, MD, U.S.A.) according to manufacturer's instructions. Total RNA (10 $\mu \mathrm{g}$ from each sample) was resolved in $1.5 \%$ agarose gels containing $0.6 \%$ formaldehyde and ethidium bromide at $0.075 \mu \mathrm{g} / \mathrm{ml}$. 
RNA was transferred onto Hybond-NX membrane (Amersham Pharmacia Biotech, Piscataway, NJ, U.S.A.) following the manufacturer's instructions. RNA blots were hybridized with ${ }^{32} \mathrm{P}$-dCTP-labeled gene-specific probes following the procedures described by Shirano and associates (2002). The hybridization probes were prepared as describe by Zhou and associates (2004a) and Shirano and associates (2002).

\section{SA measurement.}

SA and its glucoside were extracted from 0.2 to $0.5 \mathrm{~g}$ of leaf tissue and their levels were quantified by high-performance liquid chromatography as previously described (Bowling et al. 1994).

\section{Pathogen inoculation.}

Inoculation with $H$. parasitica biotype EMCO5 was performed as described by Zhou and associates (2004a), with the following modifications. Inoculations were performed on 10day-old seedlings or 4-week-old plants grown at moderate $\mathrm{RH}$ $(60 \%)$. Seedlings were sprayed with a freshly prepared suspension $\left(10^{5}\right.$ spores $\left./ \mathrm{ml}\right)$ of conidiospores suspended in water. The infected cotyledons were collected 7 days postinoculation and stained with trypan blue. The number of sporangiophores per cotyledon was counted on 80 infected cotyledons for each treatment. The infection phenotype of 4-week-old plants was scored visually and representative leaves were photographed.

\section{ACKNOWLEDGMENTS}

We thank D. Dempsey for critical reading of the manuscript, S. Xiao for communication of his data before publication, and C. Daugherty and S. Caldwell for assistance with the microscopy. This work was supported by grants (MCB-0110404 and IOB-0525360) from the National Science Foundation to D. F. Klessig and a DFG-SFB 635 grant to J. E. Parker.

\section{LITERATURE CITED}

Austin, M. J., Muskett, P., Kahn, K., Feys, B. J., Jones, J. D., and Parker, J. E. 2002. Regulatory role of SGT1 in early $R$ gene-mediated plant defenses. Science 295:2077-2080.

Azevedo, C., Sadanandom, A., Kitagawa, K., Freialdenhoven, A., Shirasu, K., and Schulze-Lefert, P. 2002. The RAR1 interactor SGT1, an essential component of $R$ gene-triggered disease resistance. Science 295:2073-2076.

Azevedo, C., Betsuyaku, S., Peart, J., Takahashi, A., Noël, L., Sadanandom, A., Casais, C., Parker, J., and Shirasu, K. 2006. Role of SGT1 in resistance protein accumulation in plant immunity. EMBO (Eur. Mol. Biol. Organ.) J. 25:2007-2016.

Bieri, S., Mauch, S., Shen, Q., Peart, J., Devoto, A., Casais, C., Ceron, F., Schulze, S., Steinbin, H. H., Shirasu, K., and Schulze-Lefert. P. 2004. RAR1 positively controls steady state levels of barley MLA resistance proteins and enables sufficient MLA6 accumulation for effective resistance. Plant Cell 16:3480-3495.

Bowling, S. A., Guo, A., Cao, H., Gordon, A. S., Klessig, D. F., and Dong, X. 1994. A mutation in Arabidopsis that leads to constitutive expression of systemic acquired resistance. Plant Cell 6:1845-1857.

Catlett, M. G., and Kaplan, K. B. 2006. Sgt1p is a unique co-chaperone that acts as a client adaptor to link Hsp90 to Skp1p. J. Biol. Chem. 281:33739-33748.

da Silva Correia, J., Miranda, Y., Leonard, N., and Ulevitch, R. 2007. SGT1 is essential for Nod1 activation. Proc. Natl. Acad. Sci. U.S.A. 104:6764-6769.

Dietrich, R. A., Delaney, T. P., Uknes, S. J., Ward, E. R., Ryals, J. A., and Dangl, J. L. 1994. Arabidopsis mutants simulating disease resistance response. Cell 77:565-577.

Freialdenhoven, A., Scherag, B., Hollricher, K., Collinge, D. B., ThordalChristensen, H., and Schulze-Lefert, P. 1994. Nar-1 and Nar-2, two loci required for mla12-specified race-specific resistance to powdery mildew in barley. Plant Cell 6:983-994.

Garcia-Ranea, J. A., Mirey, G., Camonis, J., and Valencia, A. 2002. p23 and SP20/alpha-crystallin proteins define a conserved sequence domain present in other eukaryotic protein families. FEBS (Fed. Eur. Biochem. Soc.) Lett. 529:162-167.
Gray, W. M., Muskett, P. R., Chuang, H. W., and Parker, J. E. 2003. Arabidopsis $S G T 1 b$ is required for SCF(TIR1)-mediated auxin response. Plant Cell 15:1310-1319.

Hammond-Kosack, K. E., Silverman, P., Raskin, I., and Jones, J. 1996. Race-specific elicitors of Cladosporium fulvum induce changes in cell morphology and the synthesis of ethylene and salicylic acid in tomato plants carrying the corresponding $C f$ disease resistance gene. Plant Physiol. 110:1381-1394.

Holt, B. F., Belkhadir, Y., and Dangl, J. L. 2005. Antagonistic control of disease resistance protein stability in the plant immune system. Science 309:929-932.

Hua, J., Grisafi, P., Cheng, S. H., and Fink, G. R. 2001. Plant growth homeostasis is controlled by the Arabidopsis BON1 and BAP1 genes. Genes Dev. 15:2263-2272.

Hubert, D. A., Tornero, P., Belkhadir, Y., Krishna, P., Takahashi, A., Shirasu, K., and Dangl, J. L. 2003. Cytosolic HSP90 associates with and modulates the Arabidopsis RPM1 disease resistance protein. EMBO (Eur. Mol. Biol. Organ.) J. 22:5679-5689.

Jambunathan N., and McNellis T. W. 2003. Regulation of Arabidopsis COPINE 1 gene expression in response to pathogens and abiotic stimuli. Plant Physiol. 132:1370-1381.

Jambunathan, N., Siani, J. M., and McNellis, T. W. 2001. A humidity-sensitive Arabidopsis copine mutant exhibits precocious cell death and increased disease resistance. Plant Cell 13:2225-2240.

Jones, J. D., and Dangl, J. L. 2006, The plant immune system. Nature 444:323-329.

Kachroo, P., Shanklin, J., Shah, J., Whittle, E. J., and Klessig, D. F. 2001. A fatty acid desaturase modulates the activation of defense signaling pathways in plants. Proc. Natl. Acad. Sci. U.S.A. 98:9448-9453.

Kitagawa, K., Skowyra, D., Elledge, S. J., Harper, J. W., and Hieter, P. 1999. SGT1 encodes an essential component of the yeast kinetochore assembly pathway and a novel subunit of the SCF ubiquitin ligase complex. Mol. Cell 4:21-33.

Leister, R. T., Dahlbeck, D., Day, B., Li, Y., Chesnokova, O., and Staskawicz, B. J. 2005, Molecular genetic evidence for the role of SGT1 in the intramolecular complementation of Bs2 protein activity in Nicotiana benthamiana. Plant Cell 17:1268-1278.

Li, X., Clarke, J. D., Zhang, Y., and Dong, X. 2001. Activation of an $E D S 1$-mediated $R$-gene pathway in the sncl mutant leads to constitutive, NPRl-independent pathogen resistance. Mol. Plant-Microbe Interact. 14:1131-1139.

Liu, Y., Schiff, M., Marathe, R., and Dinesh-Kumar, S. P. 2002a. Tobacco $R A R 1, E D S 1$ and NPR1/NIM1 like genes are required for $N$-mediated resistance to tobacco mosaic virus. Plant J. 30:415-429.

Liu, Y., Schiff, M., Serino, G., Deng, X. W., and Dinesh-Kumar, S. P. 2002b. Role of SCF ubiquitin-ligase and the COP9 signalosome in the $N$ gene-mediated resistance response to Tobacco mosaic virus. Plant Cell 14:1483-1496.

Liu, Y., Burch-Smith, T., Schiff, M., Feng, S., and Dinesh-Kumar, S. P. 2004. Molecular chaperone Hsp90 associates with resistance protein N and its signaling proteins SGT1 and Rar1 to modulate an innate immune response in plants. J. Biol. Chem. 279:2101-2108.

May, M. J., Hammond-Kosack, K. E., and Jones, J. D. G. 1996. Involvement of reactive oxygen species, glutathione metabolism, and lipid peroxidation in the $C f$-gene-dependent defense response of tomato cotyledons induced by race-specific elicitors of Cladosporium fulvum. Plant Physiol. 110:1367-1379.

Mayor, A., Martinon, F., De Smedt, T., Pétrilli, V., and Tschopp, J. 2007. A crucial function of SGT1 and HSP90 in inflammasome activity links mammalian and plant innate immune responses. Nat. Immunol. 8:497-503.

Meyers, B. C., Kozik, A., Griego, A., Kuang, H., and Michelmore, R. W. 2003. Genome-wide analysis of NBS-LRR-encoding genes in Arabidopsis. Plant Cell 15:809-834.

Muskett, P. and Parker, J. 2003. Role of SGT1 in the regulation of plant $R$ gene signaling. Microbes Infect. 5:969-976.

Muskett, P. R., Kahn, K., Austin, M. J., Moisan, L. J., Sadanandom, A., Shirasu, K., Jones, J. D., and Parker, J. E. 2002. Arabidopsis RAR1 exerts rate-limiting control of $R$ gene-mediated defenses against multiple pathogens. Plant Cell 14:979-992.

Peart, J. R., Lu, R., Sadanandom, A., Malcuit, I., Moffett, P., Brice, D. C., Schauser, L., Jaggard, D. A., Xiao, S., Coleman, M. J., Dow, M., Jones, J. D., Shirasu, K., and Baulcombe, D. C. 2002. Ubiquitin ligase-associated protein SGT1 is required for host and nonhost disease resistance in plants. Proc. Natl. Acad. Sci. U.S.A. 99:10865-10869.

Romano, C. P., Hein, M. B., and Klee, H. J. 1991. Inactivation of auxin in tobacco transformed with the indoleacetic acid-lysine synthetase gene of Pseudomonas savastanoi. Genes Dev. 5:438-446.

Shirano, Y., Kachroo, P., Shah, J., and Klessig, D. F. 2002. A gain-of-function mutation in an Arabidopsis Toll Interleukin1 receptor-nucleotide binding site-leucine-rich repeat type $R$ gene triggers defense responses 
and results in enhanced disease resistance. Plant Cell 14:3149-3162.

Shirasu, K., Lahaye, T., Tan, M. W., Zhou, F., Azevedo, C., and SchulzeLefert, P. 1999. A novel class of eukaryotic zinc-binding proteins is required for disease resistance signaling in barley and development in $C$. elegans. Cell 99:355-366.

Takahashi, A., Casais, C., Ichimura, K., and Shirasu, K. 2003. HSP90 interacts with RAR1 and SGT1 and is essential for RPS2-mediated disease resistance in Arabidopsis. Proc. Natl. Acad. Sci. U.S.A. 100:1177711782.

Thordal-Christensen, H., Zhang, Z., Wei, Y., and Collinge, D. B. 1997 Subcellular localization of $\mathrm{H}_{2} \mathrm{O}_{2}$ in plants. $\mathrm{H}_{2} \mathrm{O}_{2}$ accumulation in papillae and hypersensitive response during the barley-powdery mildew interaction. Plant J. 11:1187-1194.

Tör, M., Gordon, P., Cuzick, A., Eulgem, T., Sinapidou, E., Mert-Turk, F., Can, C., Dangl, J. L., and Holub, E. B. 2002. Arabidopsis SGT1b is required for defense signaling conferred by several downy mildew resistance genes. Plant Cell 14:993-1003.

Tornero, P., Merritt, P., Sadanandom, A., Shirasu, K., Innes, R. W., and Dangl, J. L. 2002. RARl and NDR1 contribute quantitatively to disease resistance in Arabidopsis, and their relative contributions are dependent on the $R$ gene assayed. Plant Cell 14:1005-1015.

Wagner, D., Przybyla, D., Op den Camp, R., Kim, C., Landgraf, F., Lee, K. P., Wursch, M., Laloi, C., Nater, M., Hideg, E., and Apel, K. 2004. The genetic basis of singlet oxygen-induced stress responses of Arabidopsis thaliana. Science 306:1183-1185.

Weymann, K., Hunt, M., Uknes, S., Neuenschwander, U., Lawton, K., Steiner, H. Y., and Ryals, J. 1995 Suppression and restoration of lesion formation in Arabidopsis lsd mutants. Plant Cell 7:2013-2022.

Xiao, S., Brown, S., Patrick, E., Brearley, C., and Turner, J. G. 2003 Enhanced transcription of the Arabidopsis disease resistance genes rpw8.1 and $r p w 8.2$ via a salicylic acid-dependent amplification circuit is required for hypersensitive cell death. Plant Cell 15:33-45.

Yang, S., and Hua, J. 2004. A haplotype-specific resistance gene regulated by bonzail mediates temperature-dependent growth control in Arabidopsis. Plant Cell 16:1060-1071.

Yoshioka, K., Kachroo, P., Tsui, F., Sharma, S. B., Shah, J., and Klessig, D. F. 2001. Environmentally sensitive, SA-dependent defense responses in the cpr22 mutant of Arabidopsis. Plant J. 26:447-459.

Zhang, Y., Goritschnig, S., Dong, X., and Li, X. 2003. A gain-of-function mutation in a plant disease resistance gene leads to constitutive activation of downstream signal transduction pathways in suppressor of nprl1, constitutive 1. Plant Cell 15:2636-2646.

Zhou, F., Andersen, C. H., Burhenne, K., Fischer, P. H., Collinge, D. B., and Thordal-Christensen, H. 2000. Proton extrusion is an essential signaling component in the HR of epidermal single cells in the barleypowdery mildew interaction. Plant J. 23:245-254.

Zhou, F., Menke, F. L., Yoshioka, K., Moder, W., Shirano, Y., and Klessig, D. F. 2004a. High humidity suppresses ssi4-mediated cell death and disease resistance upstream of MAP kinase activation, $\mathrm{H}_{2} \mathrm{O}_{2}$ production and defense gene expression. Plant J. 39:920-932.

Zhou, T., Wang, Y., Chen, J. Q., Araki, H., Jing, Z., Jiang, K., Shen, J., and Tian, D. 2004b. Genome-wide identification of $N B S$ genes in japonica rice reveals significant expansion of divergent non-TIR NBS-LRR genes. Mol. Genet. Genomics 271:402-415. 